
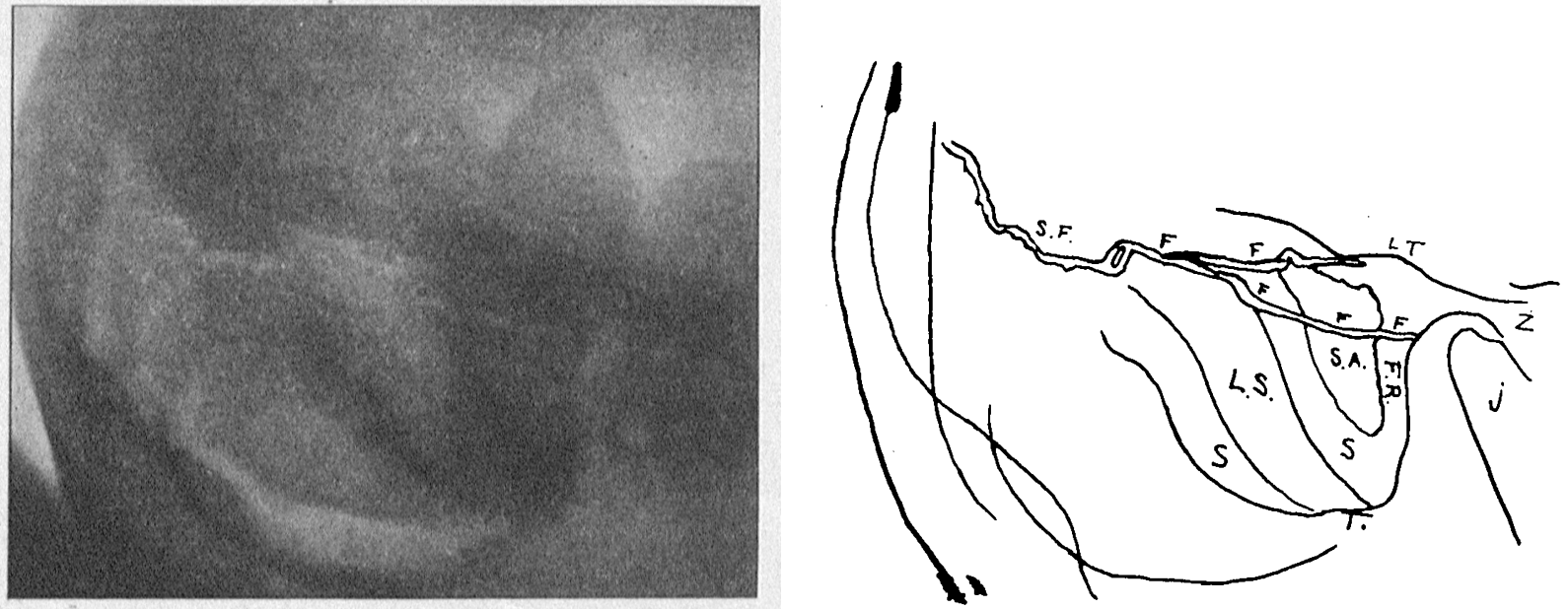

A right sclerosed mastoid showing a line of fracture. Male. Age 36. The left ear was an effectus ear and the mastoid sclerose. The richt patient had a right facial paralysis for that length of time

patient had a right facial paralysis for that length of time. FF F, line of fracture from the occipital suture (SF) across the mastoid and facial ridge (FR). $\mathrm{S} A$, softened area in the mastoid. $8 \mathrm{~S}$, sclerosed arca. $T$, mastoid tip. LS, lateral sinus. L $T$, linea temporalia $Z$, zygoma. $j$, ascending ramus of jaw

At operation the line of fracture was fou

\section{LABORATORY PHYSIOLOGY IN COLLEGE AND IN MEDICAL SCHOOL.}

By Artiun Dermont Bush, M. D., Bundngton, Vt

Instructor in l'hysiology, Univ. of Vermont, College of Medicine.

In 1885, Professor John C. Draper of the Medical Department of the University of the City of New York published his highly interesting book entitled "Medical Physics." By way of introduction he says: "It is no exaggeration to say that there is not a tissue, organ or function of the body, the proper comprehension of which does not involve a knowledge of the laws of physies. We may with equal justice affirm that there is scarcely a pirinciple of physics which is not applied in some form in the human body." He then laments the general ignorance of physics by American physicians, especially as compared with Europeans, and offers his text as a wholesome corrective. $\mathrm{He}$ deals, somewhat in extenso, with fundamental principles, but makes many pioneer applications of these principles to the science of medicine.

Nearly thirty years have passed since this work of Dr. Draper first appeared. During this period the teaching of Physics as a separate subject has been taken up by many schools, carried for a while, and subsequently dropped; not, however, without distinctly affecting methods of teaching. We take note of physical principles in pathology, surgery and hygiene, but more particularly in physiology a greater part of whose manifestations are simply phy- sical. Yet in these several branches of medicine, use is made chiefly of such of the data of physics as are directly applicable; the broad general principles are no longer taught in the medical school. We have come to see that medical science is specific, not general; deals not with the universality of law, but with the operating of universal law under particular, well-defined conditions. As a consequence of this change in our view-point a knowledge of the science of physics is now demanded not as a part of the medical course but as a necessary prerequisite. Knowledge of physical laws is, as Draper urged, essential to the proper comprehension of bodily functions, but that knowledge must be acquired where universals are taught, - in the academic side of the university; whereas a knowledge of the specific applications of those laws to the functioning human body must be learned in that department of the university devoted to the special study of the human body, to wit, in the medical school.

A similar comparison might be drawn from the methods of teaching chemistry. Not so many years ago, nearly all schools used valuable time teaching medical students fundamental principles in chemistry:- the laws of chemical combination and dissociation, nomenclature, periodicity, atomic theory, reactions and compounds of the metals and non-metals. Today, however, all of this general knowledge must be acquired before entering the medical school; and we are looking forward to the time when organic chemistry together with qualitative and quantitative analyses will also be a part of all premedical courses. Here again we recognize the principle that knowledge of general application should 
be acquired in the academic side of the University; in its place in the medical school we are to teach the application of those general laws in the determining of the problems of human metabolism, in investigating physiologic and pathologic analyses and syntheses, and in estimating all those chemical renctions characteristic of bodily activity.

Since we have accepted this welcome readjustment in the departments of physics and chemistry (moved somewhat hurriedly albeit tardily thereto by the suasion of the Council on Medieal Education), why should we not continue the good work in other departments, notably in the department of physiology? In our medical schools, in the department of physiology, we are giving courses parts of which properly helong to the work of the high school and college. We spend many long hours in the discussion and demonstration of fundamental hiological laws (c. g. nerve-muscle reactions), studies as much out of place in the rontine medical course as would be disenssions of work and energy, motion and force. We seem to assume that there are no other agencies for the teaching of physiology as a pure science, and that, perforce, we must be elementary before we can be advanced. But there exist other excellent agencies for just such elementary training; hence we have no justifiable exeuses for allowing our methods to lag ten to twenty years behind the pedagogical spirit of the times. $A s$ in ehemistry and physies, we should require that all physiological data having a general application be taught in a premedical course, so that time may be reserved in the medical course in physiology for a dealing with data conecrning human functioning specifically. "But" urges a highly-respected correspondent "there is no such thing as a human physiology; physiology is the same in frogs and cats as in man." Qualifiedly, yes; when considered as a pure science,as a problem in biology; but not so when considered as an applied science. Aside from the many variations between physiologies of the higher and lower types, it is also true that in so highly complex a specialty as modern medicine there is a specific physiology-a physiology of the living, human body concerning whose functionings and varied manifestations the medieal student needs a profomndly intimate acquaintance. Noreover, true to the growing spirit of teaching universals in the academic side of the university, and applied sejence in the professional and technical schools, we may ere long do in physiology as we have done in physies and chemistry, and insist on a premedical knowledge of biologieal prineples so that we may utilize the needed time in the medical school for studying the action of those biological laws as manifested in the human olganism. Our great obligation in the laboratory of medical physiology is to so train om students in the accurate olsservation of the multiple manifestations of the activities of the normal human mechanism that, when they enter the department of clinical medicine, they will be able to determine immediately the physiological significance of manifestations indicative of departures from the normal; students so trained would not only instantly recognize morbid conditions but they would, in the great majority of cases, be able to promptly deduce presumptive causal factors, provided, all the problems of the physiological laboratories were studied in the true spirit of investigation.

This unconventional point of view has been presented in general terms by others. Flexner (Bulletin No. 4 p. 59) says: "Physiology and pathology belong, then, in the university, beeause there is much more to them as sciences than the medical school has time for" ; also (p. 60) "Physiology as an element of a liberal education, sweeps the whole horizon impartially, interested in genetic processes, searching for general laws. It works to best advantage with simple forms, . . . with jellytish and eats in preference to man; an admirable introduction to medical physiology, but not really the same thing." Professor Matthews, of Chicago is quoted by Flexner as believing that both physiology and pathology (presumably, as general sciences) "should follow the example of physics, botany and chemistry and leave the medical faculty and be regarded as subjects prerequisite to the study of medieine" (ibid p. 60. Dr. Frederick 'T. Lewis of the Iarvard Medical School takes a different view, a view burdened with some inconsistency. In an article entitled "The Preparation for the Study of Medicine" (Popular Science Nonthly, July, 1909, 75, 65) he recommends that the matrieulant in medicine should have taken premedical courses in college in zoology, botany, chemistry, physics, psychology, history, philosophy, political economy, English, French, and German. Tnder zoology he recommends the study of morphology by vertelorate dissection, ambryology, histology and microscopic technique; but under the heading of "College Physiology" he says; "Some colleges offer comrses in physiology which are dilute presentations of medical school work." "It is wholly undesirable for the medical student to take time from other college work for the sake of such courses." This is remarkable! Why, after recommending morphology, does Dr. Lewis balk at the equally important part of zoology embodied in those manifestations of life constituting plysiology? Is not the muscle active as instructive as the muscle dead? Are not the conditions regulating activity as interesting as mere form and position? Or, again, is the study of vertebrate physiology any more of an intrusion on medieal work than vertebrate dissection is a substitute for human anatomy? For the sake of sweet reasonableness, let us paraphrase Dr. Lewis' quotation thus: "Our medieal sehools are offering courses in physiology which, because of their elementary character, belong chiefly to the college," "It is 
wholly undesirable for the medical student to take valuable time from his medical course for the sake of courses logically belonging to the academic side." 'This latter statement is really the text for Dr. Lewis' article (q. v.) for everything except physiology. Why except physiology, or rather that part of physiology which is fundamentally hiological in its scope?

To ascertain to what extent the medical school may bo duplicating work offered in secondary schools, several high school text-books were examined; and from one (Advanced Physiology and Hygiene, (Conn and Budington) the following experiments are selected from the large number given: Experiments on beef heart and valve action; beating heart of frog or turtle; capillary circulation; lacteals in mesentery of cat; ciliary movements in frog; nerve-muscle preparations from gastrocnemius of $\mathrm{frog}^{\circ}$; some characteristics of heart muscle (frog); spinal reflexes (frog); artificial eye; experiments with the "Harvard Apparatus." Are any of these omitted in the medical course?

Furthermore, to ascertain to what extent the subject of physiology is being offered in college, and the adequacy of the college course as a sub. stitute for the biological part of the present course in physiology in the medical school, an inspection was made of the catalogs of about sixty colleges, supplemented by requests for detailed information in a certain proportion of cases. The information gleaned was often unsatisfactory owing to the frequent omission of definite statements as to the actual work done in both the lecture-room and in the laboratory; so it well may be that some colleges giving satisfactory courses are not herein listed. Six colleges, Baylor, Brown, Chicago, Dartmouth, Illinois and Yale give courses in general physiology equal or superior to the courses now given in most medical schools. A part of the work at Yale is as follows: "Physiology Chemistry, a course dealing with the chemical side of Physiology. A laboratory fee of fifteen dollars is charged." 12 hrs. 2d half. "Physiology of Nutrition. A course of lectures, recitations, and demonstrations, dealing primarily with the physiology of secretion, digestion, absorption, excretion, metabolism, and other general questions bearing on the subject of animal nutrition." 2 hrs. 2nd half. "Physical and Nervous Physiology. Juectures and recitations (three hours a week) with assigned reading in a textbook, and laboratory work in the mechanics of muscle and nerve, the nervous system, the circulation and respiration." 9 hours 1 st half. $\Lambda 1$ the University of Illinois, besides histology, hygiene and research, there is offered in the department of physiology the following: "Major Course.-Physiology of nerve and muscle; circulation; secretion; respiration; digestion; metabolism. Lectures and laboratory, (Full medical credit in physiology)" 2nd semester; 10 hours a week. Prerequisites: General Physics; Chemistry-Inorganic and Organ- ice, Quantitative and Qualitative Analyses, Organic Synthesis; '/Joology ; Vertebrate, and Coinparative Anatomy, Microscopical Technique and General Vertebrate Embryology. So complete are these courses that they are fully accredited in the Medical Departments; a fact which indicates, as the Yale catalog states (p. 143), that these courses in the medical school "are of an essentially biological character." It indicates, furthermore, that we are giving an academic, premedical course in physiology in the medical school instead of the technical course that should be given. What possible excuse can there be for a continuance of this condition? Why devote weeks to biological problems when the time is vitally needed for the training of men to an intimate acquaintance with the problems of human bodily activities? The entire assignment of hours in the department of physiology is none too ample for the acquiring of accurate information concerning the mechanism of the normal human body; and, since departures from the normal constitute the student's future field of investigation, it becomes doubly imperative that his knowledge of the normal be as profound as possible. Time may be spared for no work except the strictly professional, until satisfactory proficiency permits of the assignment of correlated problems. Let no one think that any of this study of the functioning human body may be taken up in physical diagnosis, or in topographical or regional anatomy. The latter is but a necessary preparation for accuracy of work in physiology; and completeness of information in human physiology is the sine qua non for success in diagnosis.

Besides the six colleges mentioned above, the following schools give courses which seem to be ample substitutes for the biological work in the medical school: Arkansas, Alabama, Bryn Mawr, Columbia, Cornell, Georgia, Indiana, Kansas, Missouri, Nebraska, Northwestern, Ohio State, Pennsylvania, Princeton, Purdue, Wisconsin and 'T'exas. Again the question may be repeated: With twenty-two schools, at least, giving the biological work in physiology, what excuse can there be for any medical school duplicating the work? Twenty-four other schools offer courses either too elementary, or too specifically correlated with hygiene or with the teaching of physiology in secondary schools, to permit of their being added to the above list. Three schools, Boston University, Johns Hopkins and New York, offer courses in physiology to specials or gradustes only. Four schools, Bowdoin, Drake, MeGill and 'Tulane apparently offer no work in physiology. Two, at least, Dartmouth and Leland Stanford Jr. give their course in medical physiology in the academic department, a method quite at variance with the pedagogical principle this paper propounds; while seven,Cincinnati, Harvard, Jowa, Michigan, No. Dakota, 'Tufts and Utah offer academic physiology in the department of medicine, a method equally at variance with the idea herein 
proposed. My premise is that medical education should be strictly technical, whereas the work on the academic side, as Dr. Souchon and others have contended, should be concerned with universals. If this premise be granted, then the medical school has neither the time nor the "atmosphere" for teaching general laws; nor has the academic side the equipment or spirit for teaching specific applications. That such cross teaching is being done today is due ehiefly to two causes: (a) identity of subject-matter, and (b) non-recognition of the real difference in purpose of these two departments of the University. It can not be urged too often that the student has a right to the strict technical education that the needs of the community demand. Moreover, as Dr. Lewis urges (ibid p. 74), "In this great pursuit he will not become narrow. ILe will develop what Dr. James Jackson long ago described as a 'mind liberalized by scientific studies.' If he loses a certain breadth of culture because of specialization, still as Cardinal Newman has said. "the advantage of the community is nearly in inverse ratio with his own.",

It is submitted that the following subjects, now a routine part of most physiology courses in medical schools, be relegated to the academic department, where they more properly belong; there to be smelted to such values as may be useful in the development of a broad general course in general physiology: Muscle tissue experiments such as elasticity, extensibility, cohesion, consistency, irritability, contractility, time of contraction, curves, latent periods, phases of shortening and relaxation, isotonic and isometric contractions; variations in strength of stimuli, temperature, and drugs; treppe, contractures, fatigue, curve of work, summation. Electric phenomena, as demarcation current, negative variation, monophasic and diphasic action currents, rheoscopic frog, electrotonus, velocity of nerve impulse, direction of impulse, variations from external factors, refractory period, nature of nerve impulse, trophic phenomena, degeneration and regeneration. Reflex frog. General functions of the spinal cord. Characteristies of heart tissue of the poikilothermous animals. IIematology, capillary circulation, time of circulation, mechanical factors, volume curve. Automaticity of heart, and effect thereon of the salts of Na., K. and Ca. in varying percentages. "All or none" law, refractory period, compensatory pause, normal sequence, cardiac nerves and their action, vasomotor nerves. Principles and mechanies of respiration, chemical and physical changes in respired air and the relation thereto of the diffusion of gases, inncrvation of respiratory movements, variations from external factors. Gencral physiology of digestion and alimentation, ditto excretion. Physiology of glands. Decerebrate frog, decerebellate pigeon, studies on the semicircular canals of frogs and pigeons and on the saccule and utricle of the palacmon. Embryology of the chick and pig; and studies on the growth of chick and pig as affected by variations in alimentation.

These are samples of the subjects now cumbering our routine work in laboratory physiologr. No one questions their individual values as items of general physiology, or as topies for assignment in the research laboratories; and it may be admitted that a few may be utilized for purposes of demonstration; but the great mass has no place in a department presumably devoted to the training of men to an efficient knowledge of the functioning human body. Such subjects should be taken out of the medical curriculum, and in their stead should be placed studies upon such physiological phenomena as are manifest in, and demonstrable on, the body of a fellow student. To be sure, all known facts cannot thus be studied; some things must be learned by hearsay. 'The intricate, hidden details will have to be worked out by the specialist in research; his findings will be gratefully acecpted by that great body of earnest men who have neither the opportunity nor the economic necessity for such prolonged investigations. However, there is an ample supply of desirable experimental problems; and, since time and privilege are so limited, shall we not rather put our great emphasis on just that data which must inevitably serve as the major premises in all the clinical syllogisms of the practitioner's future?

Why encumber ourselves with the ghosts of the past when once freed from the chains of a halting belief? When the manufacturer of today discovers his plant not running at maximum efficiency, he directs a searching investigation to the end that wornout machines be replaced, antiquated methods be abolished, and systems demonstrably useful be introduced. Shall not the teacher as dispassionately weigh? When he finds himself burdened with excess of demands, unable to accomplish needed results because of the press of conventional tasks, shall he not bravely assume the courage of his convictions and sharpen his scalpel forthwith? The great responsibility of the teaching in the laboratory of physiology is to train the men to observe carefully, record accurately, and deduee logieally ; and the best data for this supreme work is just that which is of greatest pertinence to the life-work of the physician.

The cases of infectious diseases reported to the Boston Board of IIealth for the week ending February 24, 1914, are as follows: Diphtheria, 68 ; searlatina, 147 . of which 14 are nonresident: typhoid fever, 5 , of which 2 are nonresident; measles. 61 ; tuberculosis. 35 . of which 2 are non-resident.

The death-rate of the reported deaths for the week was 16.72 . 